\title{
Service Quality Index: A Study on Malaysian Banks
}

\author{
Khong Kok Wei \\ Sunway University College \\ E-Mail: kwkhong@sunway.edu.my
}

\begin{abstract}
The paper aimed to construct a measure in service quality for Malaysian banks. It focuses on the technique used in creating an index for service quality. The SERVQUAL model was used as the underlying theoretical framework. The quantification of service quality led to the attempt to construct an index. The index was constructed using Structural Equation Modeling (SEM) and American Customer Satisfaction Index (ACSI) as the underlying frameworks. An adapted ACSI was enhanced and improved to accommodate 2 exogenous constructs. The attempt was successful. A survey was conducted on 350 respondents where 200 were completed. Results provided evidence relevant to the literature where service attributes in service quality could improve customer satisfaction.
\end{abstract}

Keywords: SERVQUAL, ACSI, Service Quality, Service Attributes, Structural Equation Modeling (SEM), Customer Satisfaction and Malaysian Banks

\section{INTROUDUCTION}

Customers are considered as the key for any business survival whether in the B2B or B2C. The manner banks delivered their products and services would define their success within the industry. As products and customer services within the banking industry became more and more similar and substitutable, switching costs of customers were lower and affordable. The competitive nature within the industry became more challenging. Within an intense competitive industry "the bank that has the largest customer base and the highest customer retention rate will be a market leader in the industry" (Khong \& Richardson, 2002). With appropriate customer relationships management (CRM), banks could maximize the profits of each customer base (Best, 2005). In order of acquire success within the industry, banks must compete rigorously using their competitive advantages to differentiate their services. One such competitive advantage would be superior quality in customer services. Therefore, 
banks delivering quality of services better than their competitors would have greater possibilities of success (Tang \& Zairi, 1998). In order to understand the level of the banks service quality, a measurement should be in place. However quantifying service quality was complicated and too subjective. Hence this paper examined the likelihood of such quantification.

This was an exploratory paper which aimed to construct a measure for service quality in banks. The scope of the paper excluded the detailed discussion of the theoretical framework based on Parasuraman's SERVQUAL. As the SERVQUAL was a widely researched model since 1985 by Parasuraman, the literature was brief but concise. The scope of the paper also encompassed the mathematical development of a measure to quantify service quality for Malaysian Banks. Therefore it this important to highlight that the technique used to construct the above mentioned measure is the primary aim of the paper. Details follow.

\section{BRIEF LITERATURE}

Service quality was defined as the difference between the dimensions in customers' perceived service and expectations of service (Parasuraman et al., 1988). This was shown in gap 5 in figure 1. Parasuraman's SERVQUAL model was perhaps one of the most widely-used frameworks in addressing service quality. The service gap described in the model highlighted the disparity between the dimensions of expectation and perception in service experience.

Customer satisfaction was often related to the experience of consuming a particular product consisting of physical goods and services. When consumption of products fulfilled the needs and wants of consumers, they were likely to feel satisfied and contented. Since the construct in customer satisfaction was latent in nature, the quantification of this construct was complex and complicated in this paper. There were many texts that elucidated the relationship between SERVQUAL and Customer Satisfaction. One such text was from Zeithaml et al. (1993). The augmented SERVQUAL by Zeithaml et al. (1993) illustrated the association between service quality and customer satisfaction. The model also assumed linearity between service attributes to performance with customer satisfaction (Tan \& Pawitra, 2001). In this paper, service attributes to performance in banks were defined within the service dimension of Reliability, Responsiveness, Assurance, Empathy and Tangibles. Table 1 showed the measurement items (variables) in their respective dimensions that mirrored the service attributes to performance in banks. 


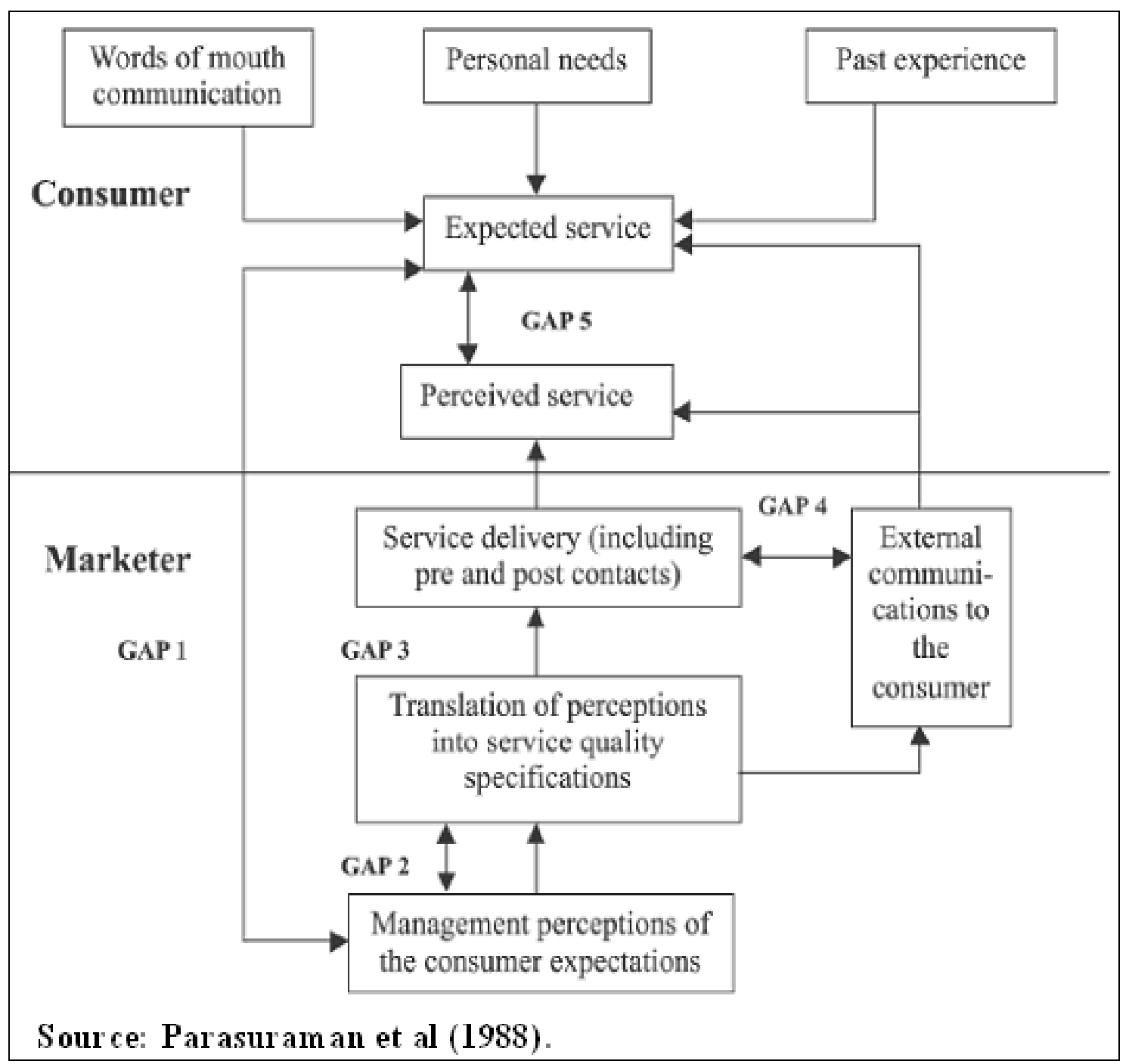

Figure 1 Parasuraman’s SERVQUAL Gap analysis Model 
Table 1 Variables used to measure the 5 dimensions

\begin{tabular}{lcl}
\hline \multicolumn{1}{c}{ Dimension } & $\begin{array}{c}\text { Variable } \\
\text { label }\end{array}$ & \multicolumn{1}{c}{ Measurement items / service attributes } \\
\hline Reliability & R1 & - providing services as promised \\
& R2 & - dependability in handling customers' problems \\
R3 & - performing services right the first time \\
R4 & - providing services at the promised time \\
& R5 & - maintaining error free records \\
R6 & - keeping customers informed about when the services will be performed \\
\hline Assurance & A1 & - employees who instill confidence in their customers \\
& A2 & - making customers feel safe in their transactions \\
& A3 & - employees who are consistently courteous \\
& A4 & - employees who have the knowledge to answer customers' questions \\
\hline Responsiveness & S1 & - prompt service to customers \\
& S2 & - willingness to help customers \\
& S3 & - readiness to respond to customers' request \\
\hline Empathy & E1 & - giving customers individual attention \\
& E2 & - employees who deal with customers in a caring fashion \\
& E3 & - having customer's best interest at heart \\
& E4 & - employees who understand the needs of their customers \\
\hline T1 & - modern looking equipment \\
T2 & - visually appealing facilities \\
& T3 & - employees who have a neat, professional appearance \\
T4 & - visually appealing materials associated with the service \\
& T5 & - convenient business hours \\
T6 & - convenient branch location \\
\hline
\end{tabular}

Source: Parasuraman et al., 1988

Using the already mentioned linearity assumption, the aim of the paper was elucidated in Figure 2. The figure shows that service attributes to performance in banks was associated with customer satisfaction. The hypothesis implied the following:

H0: Service attributes to performance have no association with customer satisfaction

H1: Service attributes to performance have association with customer satisfaction 
The strength of association between the independent and dependent dimensions depended on the regression weights established. Since there were multiple independent (23 in total) variables manifesting 5 dimensions, data reduction technique was necessary before estimation of the model. The series of statistical techniques to quantify service quality was explained in Methodology. Details follow.

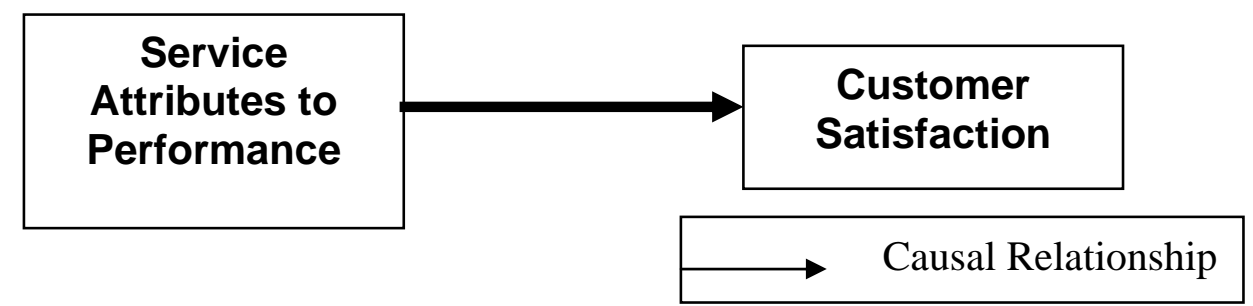

Figure 2 The causal relationship between service attributes and customer satisfaction

\section{METHODOLOGY}

The methodology comprised of two sections, ie data collection methodology and data analyses methodology.

\section{Data Collection Methodology}

Data collection was done via a survey where an instrument (questionnaire) was used to record opinions of respondents. The questionnaire comprised of questions related to opinions of respondents when experiencing the services of banks. Opinions ranged from expected services, predicted services and perceived services within the 5 dimensions of service quality (see Table 1). The mode of contact with respondents was face-to-face in ten major malls in the Klang Valley. Each mall was allotted 35 questionnaires. From the 350 questionnaires via mall intercept, 200 questionnaires were completed; a 57\% response rate. 14 of them were discarded for further analyses due to too many missing values. Although the sample size was unlikely to generalise the population, it was enough for the series of statistical tests (Hair et al., 1998).

\section{Data Analyses Methodology}

A series of statistical techniques were required before the quantification of service quality. These statistical analyses were conducted using SPSS; a widely used statistical software package. The statistical techniques conducted were: 

(a) Reliability Test (using SPSS)
(b) Exploratory Factor Analysis (using SPSS)
(c) Confirmatory Factor Analysis (using SPSS and SPSS AMOS)
(d) Structural Equation Modelling (using SPSS AMOS)

\section{- Reliability Test (Internal Consistency)}

Reliability test, being the most widely used method to measure internal consistency, was conducted on the 23 variables bearing a Cronbach's alpha of 0.7 and above (Cronbach's alpha $=0.969$ ). The results inferred the questionnaire was measuring service quality in a meaningful way.

\section{- Exploratory Factor Analysis (EFA)}

EFA is a data reduction technique to examine "possible relationships in only the most general form and then allows the multivariate technique to estimate relationships" (Hair et al, 1998, p 580). The objective of EFA in this paper was to observe the pattern of manifestation of variables on the factors extracted. EFA was extracted using principal component matrix and rotated via Promax. EFA extracted 2 factors which were not exactly what the literature would have suggested. The convergence of 23 variables into 2 factors was explained in the CFA. Total variance accounted for by the 2 factors was approximately $69 \%$.

\section{- Confirmatory Factor Analysis (CFA)}

CFA is also known as measurement model. When conducting CFA, variables were assigned to manifest a particular factor, now called a construct, where the manifestation or factor loadings were the highest. When variables had confirmed their manifestation on either constructs based on their highest factor loadings, the service attributes (variables) were manifesting two significant constructs, ie Tangibles and Intangibles (see Table 3). The results inferred some consistency with the literature where Construct 1 was a manifestation of service dimension such as Reliability, Assurance, Responsiveness and Empathy while Construct 2 was a manifestation of Tangibles (see Table 1). 
Table 2 EFA extrated via Principal Component Matrix rorated via Promax

\begin{tabular}{ccc}
\hline & \multicolumn{2}{c}{ Factors } \\
& 1 & 2 \\
\hline T1 & .590 & .850 \\
T2 & .564 & .853 \\
T3 & .557 & .765 \\
T4 & .604 & .881 \\
T5 & .577 & .782 \\
T6 & .489 & .677 \\
R1 & .777 & .715 \\
R2 & .782 & .649 \\
R3 & .822 & .651 \\
R4 & .819 & .638 \\
R5 & .756 & .539 \\
R6 & .790 & .628 \\
S1 & .831 & .608 \\
S2 & .857 & .622 \\
S3 & .879 & .658 \\
A1 & .825 & .564 \\
A2 & .817 & .559 \\
A3 & .893 & .587 \\
A4 & .859 & .618 \\
E1 & .846 & .555 \\
E2 & .899 & .587 \\
E3 & .866 & .566 \\
E4 & .840 & .581 \\
\hline & &
\end{tabular}

In order to mathematically notate the measurement models, let the general equation of the measurement models for Construct 1 (Intangibles) and 2 (Tangibles) be given as:

$$
\begin{aligned}
& Z=\Lambda_{z} \xi_{z}+\delta \ldots(1) \\
& X=\Lambda_{x} \xi_{x}+\delta \ldots(2)
\end{aligned}
$$


Table 3 CFA assigned variables manifesting a particular construct

\begin{tabular}{cccc} 
& $\begin{array}{c}\text { Variables } \\
\text { relabeled }\end{array}$ & 1 & Construct \\
\hline $\mathrm{T} 1$ & $\mathrm{X}_{1}$ & & .850 \\
$\mathrm{~T} 2$ & $\mathrm{X}_{2}$ & & .853 \\
$\mathrm{~T} 3$ & $\mathrm{X}_{3}$ & & .765 \\
$\mathrm{~T} 4$ & $\mathrm{X}_{4}$ & & .881 \\
$\mathrm{~T} 5$ & $\mathrm{X}_{5}$ & & .782 \\
$\mathrm{~T} 6$ & $\mathrm{X}_{6}$ & & .677 \\
$\mathrm{R} 1$ & $\mathrm{Z}_{1}$ & .777 & \\
$\mathrm{R} 2$ & $\mathrm{Z}_{2}$ & .782 & \\
$\mathrm{R} 3$ & $\mathrm{Z}_{3}$ & .822 & \\
$\mathrm{R} 4$ & $\mathrm{Z}_{4}$ & .819 & \\
$\mathrm{R} 5$ & $\mathrm{Z}_{6}$ & .756 & \\
$\mathrm{R} 6$ & $\mathrm{Z}_{7}$ & .790 & \\
$\mathrm{~S} 1$ & $\mathrm{Z}_{8}$ & .831 & \\
$\mathrm{~S} 2$ & $\mathrm{Z}_{9}$ & .857 & \\
$\mathrm{~S} 3$ & $\mathrm{Z}_{10}$ & .879 & \\
$\mathrm{~A} 1$ & $\mathrm{Z}_{11}$ & .825 & \\
$\mathrm{~A} 2$ & $\mathrm{Z}_{12}$ & .817 & \\
$\mathrm{~A} 3$ & $\mathrm{Z}_{13}$ & .893 & \\
$\mathrm{~A} 4$ & $\mathrm{Z}_{14}$ & .859 & \\
$\mathrm{E} 1$ & $\mathrm{Z}_{15}$ & .846 & \\
$\mathrm{E} 2$ & $\mathrm{Z}_{16}$ & .899 & \\
E3 & $\mathrm{Z}_{17}$ & .866 & \\
E4 & $\mathrm{Z}_{18}$ & .840 & \\
& & & \\
\hline & & & \\
\hline
\end{tabular}

where $\xi_{z}$ was the exogenous construct 1 and $\xi_{x}$ was the exogenous construct 2. $\delta$ was the measurement error for constructs 1 and 2 (note $\mathrm{E}(\delta)=0$ ) (Anderson \& Fornell, 2000). The corresponding equation for (1) and (2) could be written as: 
Construct 1 (Intangibles):

$\left(\begin{array}{l}Z_{1} \\ Z_{2} \\ Z_{3} \\ Z_{4} \\ Z_{5} \\ Z_{6} \\ Z_{7} \\ Z_{8} \\ Z_{9} \\ Z_{10} \\ Z_{11} \\ Z_{12} \\ Z_{13} \\ Z_{14} \\ Z_{15} \\ Z_{16} \\ Z_{17}\end{array}\right)=\left(\begin{array}{l}\lambda_{1}^{Z} \\ \lambda_{2}^{Z} \\ \lambda_{3}^{Z} \\ \lambda_{4}^{Z} \\ \lambda_{5}^{Z} \\ \lambda_{6}^{Z} \\ \lambda_{7}^{Z} \\ \lambda_{8}^{Z} \\ \lambda_{9}^{Z} \\ \lambda_{10}^{Z} \\ \lambda_{11}^{Z} \\ \lambda_{12}^{Z} \\ \lambda_{13}^{Z} \\ \lambda_{14}^{Z} \\ \lambda_{15}^{Z} \\ \lambda_{16}^{Z} \\ \lambda_{17}^{Z}\end{array}\right) \xi_{Z}+\left(\begin{array}{l}\delta_{1} \\ \delta_{2} \\ \delta_{3} \\ \delta_{4} \\ \delta_{5} \\ \delta_{6} \\ \delta_{7} \\ \delta_{8} \\ \delta_{9} \\ \delta_{10} \\ \delta_{11} \\ \delta_{12} \\ \delta_{13} \\ \delta_{14} \\ \delta_{15} \\ \delta_{16} \\ \delta_{17}\end{array}\right) \ldots$

Construct 2(Tangibles):

$$
\left(\begin{array}{l}
X_{1} \\
X_{2} \\
X_{3} \\
X_{4} \\
X_{5} \\
X_{6}
\end{array}\right)=\left(\begin{array}{l}
\lambda_{1}^{X} \\
\lambda_{2}^{X} \\
\lambda_{3}^{X} \\
\lambda_{4}^{X} \\
\lambda_{5}^{X} \\
\lambda_{6}^{X}
\end{array}\right) \xi_{X}+\left(\begin{array}{l}
\delta_{18} \\
\delta_{19} \\
\delta_{20} \\
\delta_{21} \\
\delta_{22} \\
\delta_{23}
\end{array}\right) \ldots(4)
$$




\section{- Structural Equation Modelling (SEM)}

SEM was used to estimate the model (see Figure 3). SPSS AMOS was used as the statistical software package in the model estimation. The values displayed in the figure were unstandardised estimates. Unstandardised estimates, where the input matrix used was the variance covariance matrix, were used to formulate the equation of the structural model. "When testing a series of causal relationships, covariances were the preferred input matrix type" because this matrix was essential in theory testing (Hair et al., 1998, p 631). The underlying assumption of SEM was that the dependence relationships among constructs were assumed to be linear; an assumption similar with the Literature. This assumption meant that Constructs 1 and 2 were linearly associated with customer satisfaction. Constructs 1 and 2 were correlated hence the Promax rotation in EFA.

In order to mathematically notate the structural model, let the general equation of the structural model be given as:

$$
\eta=\gamma \xi+\beta \eta+\zeta
$$

where $\gamma_{z}$ and $\gamma_{x}$ were the associations between the exogenous constructs $1 \& 2$ respectively with the criterion customer satisfaction $\left({ }^{\eta}\right) . \zeta$ was the measurement error for customer satisfaction $\left({ }^{\eta}\right)$ as shown in Figure 3 (note $\mathrm{E}(\zeta)=0, \beta \eta=$ $0)$ (Anderson \& Fornell, 2000). The figure elucidated the dependence relationships specifying the structural and measurement models given in equations (1) and (5). Based on these equations, the structural model would be notated as:

$$
\eta=\gamma_{z} \xi_{z}+\gamma_{x} \xi_{x}+\zeta_{1} \ldots
$$

Using the unstandardised estimates from the dataset, the equation could be simplified as:

$$
\eta=0.48 \xi_{z}+0.34 \xi_{x} \ldots(7)
$$

in testing the hypothesis proposed earlier, results in table 4 showed there was sufficient evidence to suggest that the service attributes to performance in banks were positively associated with customer satisfaction. This hypothesis test results were inline with the Literature (see Table 4). 


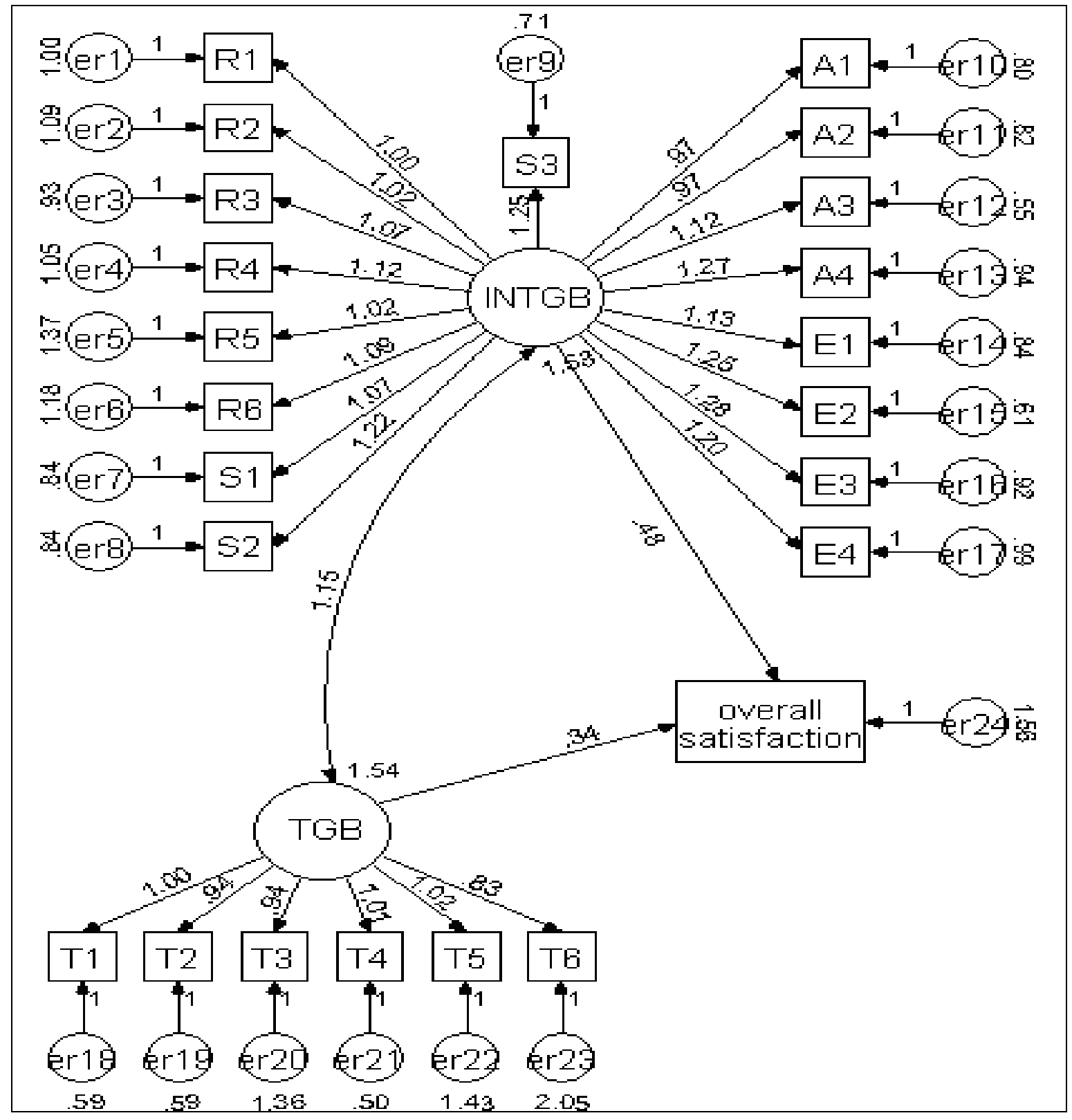

Note: overall satisfaction refers to overall customer satisfaction INTGB refers to Intangibles (Construct 1)

TGB refers to Tangibles (Construct 2)

Values shown are unstandardised estimates

(variance covariance matrix was used as the input matrix)

Figure 3: SEM results 
Table 4 Results of significant dependence relationships among constructs

\begin{tabular}{ccccc}
\hline $\begin{array}{c}\text { Construct } \\
\text { Associations }\end{array}$ & $\alpha$ level & $\begin{array}{c}\text { Unstandardised } \\
\text { Estimates (UE) }\end{array}$ & p-value & Inference \\
\hline$\xi_{\mathrm{z}}$ with $\eta$ & 0.05 & 0.48 & 0.006 & Positive association \\
$\xi_{\mathrm{x}}$ with $\eta$ & 0.05 & 0.34 & 0.000 & Positive association \\
$\xi_{\mathrm{x}}$ with $\xi_{\mathrm{z}}$ & 0.05 & 1.15 & 0.000 & $\begin{array}{c}\text { Positive } \\
\text { covariance/correlation }\end{array}$ \\
\hline
\end{tabular}

\section{CONSTRUCTING AN INDEX FOR SERVICE QUALITY}

Index is referred to as a scale that reflects a parameter of values ranging from objective to subjective measures relative to a based number. Subjective measures such customer satisfaction, service quality and customer experiences were difficult to quantify. Therefore creating an index based on subjective measures was complicated. Furthermore, construction of an index based on SEM as the underlying statistical framework further complicated the matter. Texts available in the literature that performed such empirical research were limited and scarce. However there was one text by Professor Claes Fornell and his colleagues in their research on American Customer Satisfaction Index (ACSI) (Fornell et al., (1996). Referring to Anderson \& Fornell (2000), the ACSI framework was mathematically notated as:

$$
A C S I=\frac{\sum_{i=1}^{3} w_{i} \bar{x}_{i}-\sum_{i=1}^{3} w_{i}}{9 \sum_{i=1}^{3} w_{i}} \times 100 \ldots \text { (8) }
$$

where $w_{i} s$ are the unstandardised regression weights and $x_{i} s$ are the manifesting variables.

The ACSI was based on an exogenous construct for customer satisfaction, ie customer expectations. Since customer expectations was the only exogenous construct in the model, equation (8) prevailed. To make it short but concise, the ACSI was equated based on a single exogenous construct. Should there be more than one exogenous construct; equation (8) required further extension. The construction of the service quality index was fundamentally based on the framework of ACSI. 


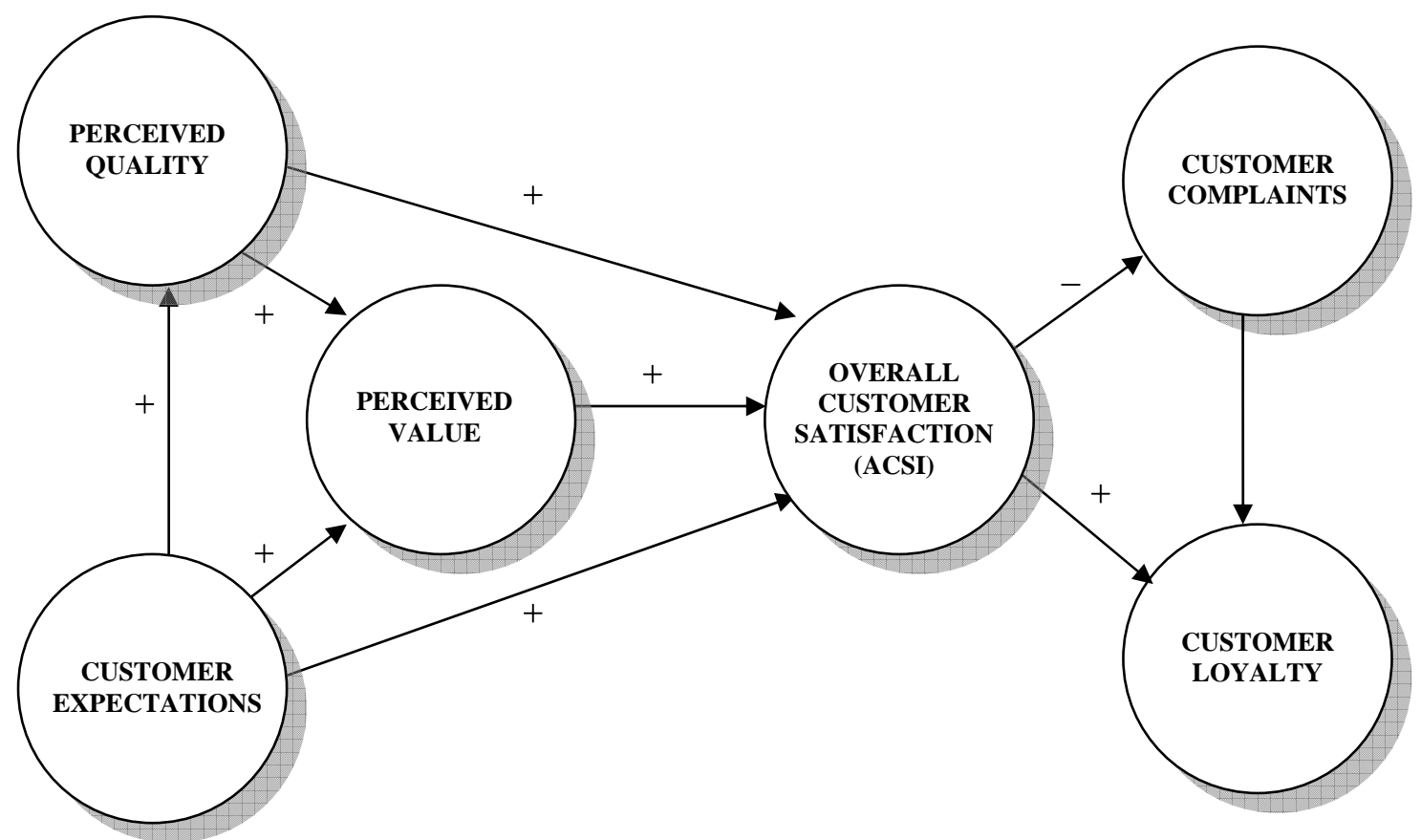

Source: Fornell et al. (1996)

Figure 4 The ACSI model

Referring to Figure 3, the structural model of this paper had 2 exogenous constructs. When calculating the index encompassing 2 correlated exogenous constructs, it was crucial to highlight the partial effects of one another on the criterion. The correlation among exogenous constructs effected the multiple correlations (R) on the criterion. As a result, the total variance explained $\left(R^{2}\right)$ of the criterion had to be adjusted for $\mathrm{R}$ as well. First let this equation be notated as:

$$
\hat{s}=\gamma_{z} s_{z}+\gamma_{x} s_{x}
$$

where $\mathrm{S}_{\mathrm{z}}$ and $S_{x}$ were the standardised estimates on constructs 1 and 2 respectively (note: They represented the constructs Intangible and Tangible). $\hat{s}$ was the standardised predicted estimates for the criterion while $\gamma_{z}$ and $\gamma_{x}$ were the standardised regressions weights for exogenous constructs 1 and 2 respectively. Equation (9) was somewhat similar to that found in equation (7). Then let $\gamma_{z}$ and $\gamma_{x}$ be respectively notated as:

$$
\begin{gathered}
\gamma_{z}=\frac{r_{y z}-r_{y x} \phi_{z x}}{1-\phi_{z x}^{2}} \ldots \\
\gamma_{x}=\frac{r_{y x}-r_{y z} \phi_{z x}}{1-\phi_{z x}^{2}} \ldots
\end{gathered}
$$


where $\phi$ was the correlation of exogenous constructs and $r_{y}$ was the bivariate correlations of constructs 1 and 2 respectively.

Assuming the $R^{2}$ of customer satisfaction (criterion) was linearly regressed on the exogenous constructs (see Literature), the degree of changes in service quality would depend of the changes in these constructs. Consequently, the service quality index would also change based on the impact of these exogenous constructs. Therefore let the service quality index be expressed as a function of $\Gamma, \Phi$ and $I$. Consequently, let

$$
\frac{\sum_{i=1}^{3} w_{i} \bar{Z}_{i}-\sum_{i=1}^{3} w_{i}}{9 \sum_{i=1}^{3} w_{i}} \times 100=I_{z} \text { and } \frac{\sum_{i=1}^{3} w_{i} \bar{x}_{i}-\sum_{i=1}^{3} w_{i}}{9 \sum_{i=1}^{3} w_{i}} \times 100=I_{x}
$$

Hence the notation:

$$
S Q I=\frac{\gamma_{z} r_{y z}}{\gamma_{z} r_{y z}+\gamma_{x} r_{y x}}\left(I_{z}\right)+\frac{\gamma_{x} r_{y x}}{\gamma_{z} r_{y z}+\gamma_{x} r_{y x}}\left(I_{x}\right)
$$

or

$$
S Q I=\left(\frac{1}{\gamma_{z} r_{y z}+\gamma_{x} r_{y x}}\right)\left(\gamma_{z} r_{y z} I_{z}+\gamma_{x} r_{y x} I_{x}\right)
$$

Therefore the SQI based on the dataset would be 54.57 where $r_{y z}=0.584, r_{y x}=0.556$, $\gamma_{z}=0.38, \gamma_{x}=0.27, I_{z}=54.47$ and $I_{x}=54.7$.

\section{DISCUSSION AND CONCLUSION}

It must be highlighted that the paper did not intend to declare that 54.57 fell short of any expected threshold within the index. The attempt to index was to justify the feasibility in quantifying service quality. The question of whether the index was not up to expectation was left unanswered. However there were several texts indicating the threshold of 0.7 and above. Failing to meet this threshold would mean the service quality was not up to standard. Based on the dataset, the service dimension of intangibles had a higher possibility to improve customer satisfaction. Manifesting variables such as A4, E2, E3, E4, A4 and S2 had the highest multiple correlations stipulating their importance in contributing to higher customer satisfaction. 
Table 5 Variables that can better enhance customer satisfaction in the service dimension

\begin{tabular}{lcl}
\hline Dimension & $\begin{array}{c}\text { Variable } \\
\text { label }\end{array}$ & Measurement items / service attributes \\
\hline Assurance & A4 & - employees who have the knowledge to answer customers' questions \\
Responsiveness & S2 & - willingness to help customers \\
Empathy & E2 & - employees who deal with customers in a caring fashion \\
& E3 & - having customer's best interest at heart \\
& E4 & - employees who understand the needs of their customers \\
\hline
\end{tabular}

The hypothesis inferred relevance to the literature. It implied that the service attributes to performance had positive association with customer satisfaction.

In order to benefit from the service quality index, banks must constantly benchmark their service levels based on their service attributes to performance. From these indices, banks could identify inadequacies in their service quality. With inadequacies established, banks could distinguish essential service attributes that offer the highest possibilities in enhancing the criterion, eg. customer satisfaction or business performance. The complexity and difficulty of creating an index using SEM and ACSI as the underlying frameworks were displayed in this paper. The index could only handle 2 correlated exogenous constructs at the moment. If there were more than 2 exogenous constructs, the shared impact on the criterion among the constructs could be too complicated. However this was the intention for future research. With more intense identification of service attributes of banks in Malaysia, while taking in account the possibility of multiple correlated exogenous constructs, the construction of a service quality index could prove to be a worthwhile effort.

\section{REFERENCES}

Anderson, E., \& Fornell, C. (2000). Foundations of the American Customer Satisfaction Index. Total Quality Management, 11(7), 869-883.

Best, R. (2005). Market Based Management(4th International 3d.).Maidenhead: McGraw-Hill.

Fornell, C., Johnson, M. D, Anderson, E.W, Cha, J., \& Bryant, B.E. (1996). The American Customer Satisfaction Index: Nature, purpose, and findings. Journal of Marketing, 60(4), 7-18

Hair, J.F., Anderson, R.E., Tatham, R.L., \& Black, W.C. (1998). Multivariate Analysis (5th ed.). New Jersey: Prentice Hall International.

Khong, K.W., \& Richardson, S. (2002). Business Process Re-engineering: a 
comparison with other management techniques. The Journal of the Institute of Bankers Malaysia, 4(119), 32-44.

Tang, K.H., \& Zairi, M. (1998). Benchmarking quality implementation in a service context: A comparative analysis of financial services and institutions of higher education, Part I: Financial services sector. Total Quality Management, 9(6), 407-420.

Parasuraman, A., Zeithaml, V.A., \& Berry, L.L. (1988). SERVQUAL: A MultipleItem Scale for Measuring Consumer Perceptions of Service Quality. Journal of Retailing, 64(1), 12-40.

Tan, K.C., \& Pawitra, T.A. (2001). Integrating SERVQUAL and Kano's model into QFD for service excellence development. Managing Service Quality, 11(6), 418430.

Zeithaml, V.A., Berry, L.L., \& Parasuraman, A. (1993). The nature and determinants of customer satisfaction of services. Journal of the Academy of Marketing Science, 21(1), 1-12. 